\title{
Preservation of the metabolic rate of oxygen in preterm infants during indomethacin therapy for closure of the ductus arteriosus
}

\author{
Rohit Arora', Mustafa Ridha' ${ }^{2,3}$, David S. C. Lee ${ }^{1}$, Jonathan Elliott ${ }^{2,3}$, Herschel C. Rosenberg ${ }^{4}$, Mamadou Diop ${ }^{2,3}$, Ting-Yim Lee ${ }^{2,3,5}$ \\ and Keith St. Lawrence ${ }^{2,3}$
}

BACKGROUND: The aim of this study was to assess and quantify the effects of indomethacin on cerebral blood flow (CBF), oxygen extraction fraction (OEF), and cerebral metabolic rate of oxygen $\left(\mathrm{CMRO}_{2}\right)$ in preterm infants undergoing treatment for a patent ductus arteriosus (PDA).

METHODS: $\mathrm{CBF}$ and $\mathrm{CMRO}_{2}$ were measured before and after the first dose of a 3-d course of indomethacin to close hemodynamically significant PDA in preterm neonates. Indocyaninegreen (ICG) concentration curves were acquired before and after indomethacin injection to quantify $\mathrm{CBF}$ and $\mathrm{CMRO}_{2}$.

RESULTS: Eight preterm neonates (gestational age, $27.6 \pm 0.5$ wk; birth weight, $992 \pm 109 \mathrm{~g} ; 6$ males: 2 females) were treated at a median age of $4.5 \mathrm{~d}$ (range, 4-21 d). Indomethacin resulted in an average CBF decrease of $18 \%$ (pre- and post$\mathrm{CBF}=12.9 \pm 1.3$ and $10.6 \pm 0.8 \mathrm{ml} / 100 \mathrm{~g} / \mathrm{min}$, respectively) and an OEF increase of $11 \%$ (pre- and post-OEF $=0.38 \pm 0.02$ and $0.42 \pm 0.02$, respectively) but no significant change in $\mathrm{CMRO}_{2}$ (pre- and post-CMRO $=0.83 \pm 0.07$ and $0.76 \pm 0.07 \mathrm{ml}$ $\mathrm{O}_{2} / 100 \mathrm{~g} / \mathrm{min}$, respectively). Corresponding mean blood pressure (BP), arterial oxygen saturation $\left(\mathrm{S}_{\mathrm{a}} \mathrm{O}_{2}\right)$, heart rate, and endtidal carbon dioxide tension levels remained unchanged.

CONCLUSION: Indomethacin resulted in significant reduction in CBF but did not alter $\mathrm{CMRO}_{2}$ because of a compensatory increase in OEF.

T he incidence of patent ductus arteriosus (PDA) is inversely related to birth weight and gestational age; $40 \%$ of infants with PDA are below $1,000 \mathrm{~g}$ or of a gestational age $<28 \mathrm{wk}$ $(1,2)$. Preterm infants with PDA are at greater risk of pulmonary edema and hemorrhage, bronchopulmonary dysplasia, and decreased perfusion and oxygen delivery to the organs, including the brain (3). Reduced cerebral perfusion has been implicated in the higher incidence of intraventricular hemorrhage and periventricular leucomalacia $(4,5)$. Consequently, management of preterm infants with clinically significant PDA has focused on ductal closure by either nonsteroidal antiinflammatory drugs or, if necessary, surgical ligation.
Primary treatment is typically with a cyclooxygenase inhibitor, either indomethacin or ibuprofen $(6,7)$. These drugs inhibit the production of prostaglandins, causing a functional constriction of the ductus arteriosus, which induces anatomical remodeling and ultimately ductal closure. Both drugs are equally effective, with a success rate between 60 and $80 \%$ (8). However, a well-known difference between indomethacin and ibuprofen is the vasoconstricting effect of the former, which has been shown to reduce renal and cerebral perfusion. Cerebral blood flow (CBF) reductions ranging from 12 to $40 \%$ have been reported using a variety of blood flow measurement techniques, including the ${ }^{133}$ Xenon clearance technique (9), near-infrared spectroscopy (NIRS) (10,11), and Doppler ultrasound $(12,13)$. Considering that this is a patient population that is already at high risk of brain injury, alterations in cerebral hemodynamics as a consequence of PDA treatment remain a concern (7), particularly if these reductions are large enough to affect cerebral energy metabolism.

NIRS studies have shown that indomethacin can alter cerebral oxygenation such as the fractional tissue oxygen extraction, although the magnitude of the changes appears to depend on the infusion protocol $(5,14,15)$. Interpreting cerebral oxygenation in terms of energy metabolism is difficult because cerebral blood oxygenation depends on the balance between oxygen delivery and consumption. Earlier studies investigating the effects of indomethacin on cerebral cytochrome oxidase reported reduction in the oxidized state (16-18). However, no study has directly measured the effects of indomethacin on the cerebral metabolic rate of oxygen $\left(\mathrm{CMRO}_{2}\right)$, despite the ability of NIRS to determine $\mathrm{CMRO}_{2}$ by combining cerebral flow and oxygenation measurements (19-21).

The purpose of the current study was to measure CBF, oxygen extraction fraction $(\mathrm{OEF})$, and $\mathrm{CMRO}_{2}$ in preterm infants who were undergoing treatment with indomethacin for a hemodynamically significant PDA. Measurements were obtained before and immediately following the infusion of the first dose of the drug, which was part of a standard three-dose (one dose 
per day) protocol. CBF was measured with a bolus-tracking NIRS technique using the light-absorbing dye indocyanine green (ICG) as an intravascular contrast agent (22). This dye has been used previously to measure CBF in preterm infants and has a good safety record: the incidence of systemic allergic reactions is $\sim 1: 250,000(23,24)$. $\mathrm{CMRO}_{2}$ was determined by combining NIRS measurements of CBF and the cerebral concentration of deoxyhemoglobin [HHb] (25).

\section{RESULTS}

Complete data sets (i.e., both NIRS and the dye densitometer data before and after first treatment dose) were obtained from 8 of 10 infants. Data from the remaining two sets were excluded because of poor-quality arterial ICG concentration curves as a result of motion artifacts. Baseline clinical details from the remaining infants are given in Table 1 . The studied cohort had a gestational age (mean \pm SE) of $27.6 \pm 0.5 \mathrm{wk}$ and a birth weight of $992 \pm 109 \mathrm{~g}$. The median age of treatment was $4.5 \mathrm{~d}$ (range; 4-21 d).

Figure 1 illustrates arterial and tissue ICG concentration curves, pre- and post-treatment, from one infant. These curves show the typical first pass of ICG in blood and brain due to the rapid bolus injection of the dye. The magnitude of the first pass is diminished after indomethacin infusion (Figure 1b), reflecting the reduction in CBF. In this example, $\mathrm{CBF}$ decreased from 17.7 to $11.8 \mathrm{ml} / 100 \mathrm{~g} / \mathrm{min}$ after indomethacin treatment. Figure 2 shows the individual pre- and post-treatment values of $\mathrm{CBF}$, cerebral blood volume (CBV), OEF, and $\mathrm{CMRO}_{2}$. A general reduction in $\mathrm{CBF}$ and $\mathrm{CBV}$ was observed as expected due to the known vasoconstricting effects of indomethacin. A concurrent increase in OEF was found, whereas $\mathrm{CMRO}_{2}$ displayed no significant change. These observations were confirmed by the mean pre- and post-treatment values given in Table 2. Indomethacin caused a significant decrease in CBF

Table 1. Baseline clinical parameters

\begin{tabular}{lc}
\hline Parameter & Value \\
\hline Gestational age (weeks) & $27.6 \pm 0.5$ \\
Birth weight (g) & $992 \pm 109$ \\
Gender (M/F) & $6: 2$ \\
Apgar score at 1 min (median (range)) & $3(1-8)$ \\
Apgar score at 5 min (median (range)) & $6(2-9)$ \\
Mechanically ventilated (\%) & \\
IMV & 75 \\
CPAP & 25 \\
HFV & 0
\end{tabular}

Total hemoglobin (g/dl)

$13.3 \pm 0.6$

IVH grade (\%)

of $18 \%(P<0.025)$ and in CBV of $15 \%(P<0.02)$. There was a significant increase in OEF of $11 \%(P<0.025)$, but the drug had no overall effect on $\mathrm{CMRO}_{2}$.

Included in Table 2 are the mean values of arterial oxygen saturation $\left(\mathrm{S}_{\mathrm{a}} \mathrm{O}_{2}\right)$, heart rate, mean blood pressure $(\mathrm{BP})$, and transcutaneous carbon dioxide before and after treatment; none of them were found to change significantly after the drug infusion. The PDA was closed in all eight cases after the threedose regimen of indomethacin. Five ducts remained closed whereas three reopened at a later time and received further indomethacin courses. One of the three cases responded to the second course of indomethacin, whereas the remaining two underwent surgical ligation.

\section{DISCUSSION}

The principal finding of this study was that, despite the significant reductions in $\mathrm{CBF}$ and $\mathrm{CBV}$ caused by a 30-min infusion of indomethacin, there was no change in $\mathrm{CMRO}_{2}$. This finding was not unexpected, considering that under normal conditions, $\mathrm{CMRO}_{2}$ should remain stable during relatively moderate reductions in $\mathrm{CBF}$ due to a compensatory increase in OEF. In this study, the $18 \%$ reduction in $\mathrm{CBF}$ was accompanied by a statistically significant increase in OEF of $11 \%$. These results suggest that, even at this very early age, the cerebral oxygen
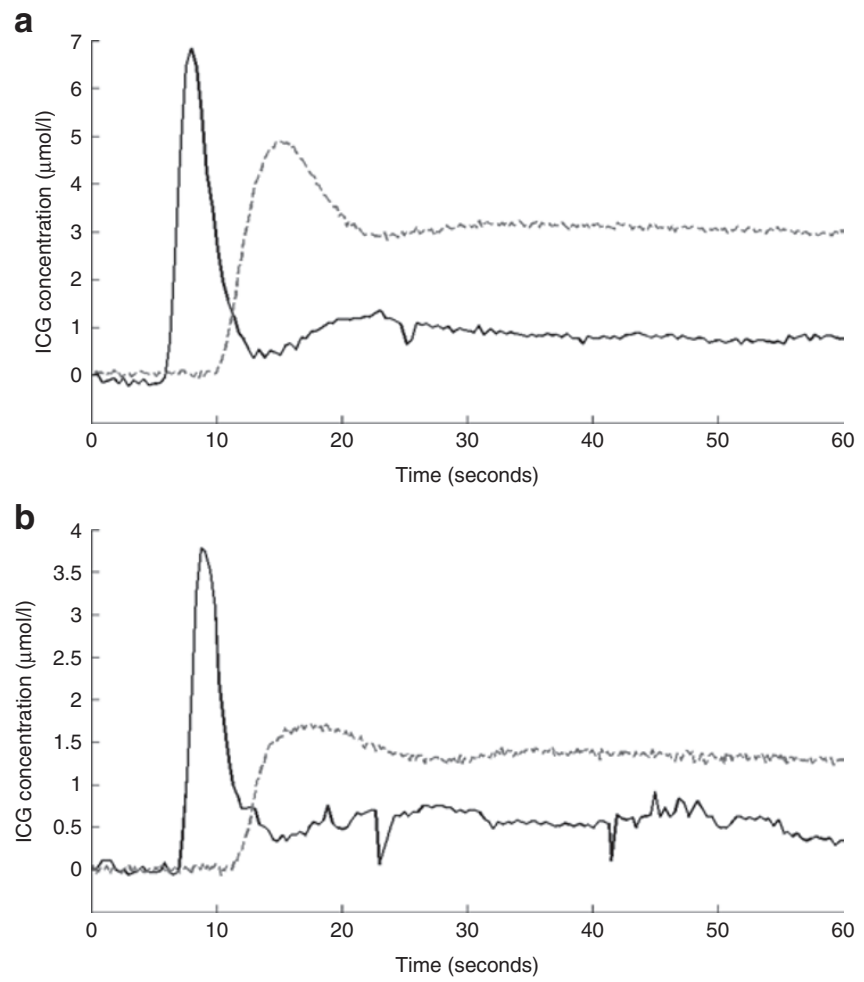

Figure 1. Arterial (solid line) and brain (dashed line) ICG concentration curves measured by dye densitometry and near-infrared spectroscopy, respectively. Data shown are from one infant (a) before and (b) after first treatment dose of indomethacin. Each set of arterial and tissue curves was measured simultaneously after injecting a solution of ICG $(0.1 \mathrm{mg} / \mathrm{kg}$ at a concentration of $0.5 \mathrm{mg} / \mathrm{ml}$ ). For visualization, the tissue curves have been scaled by a factor of 20 because the cerebral blood volume is $5 \%$ of the total tissue volume. ICG, indocyanine green. 
a

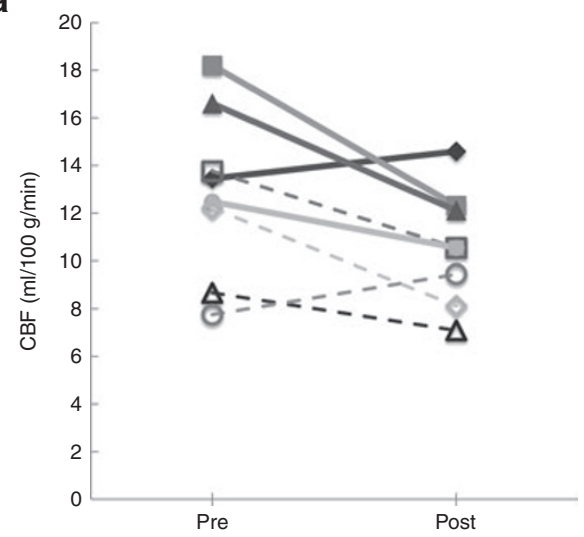

C

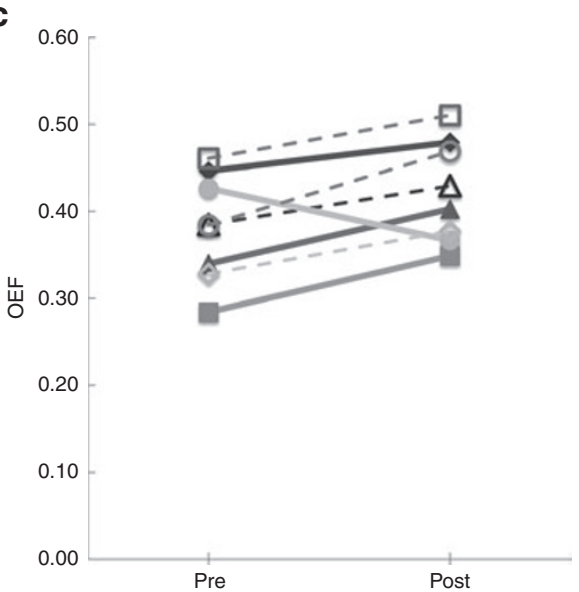

b

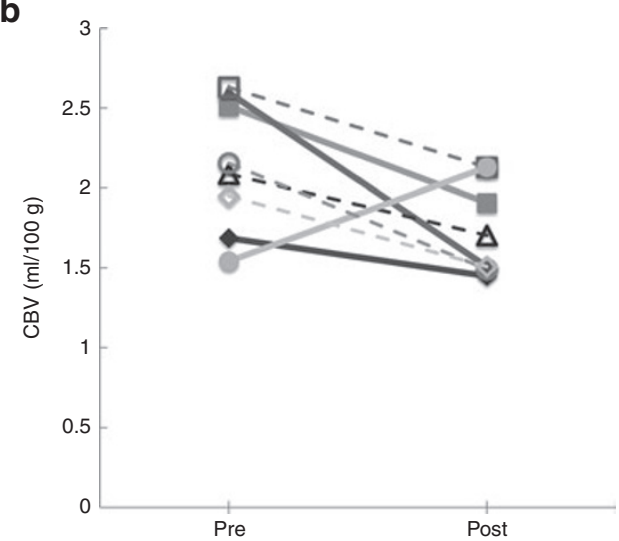

d

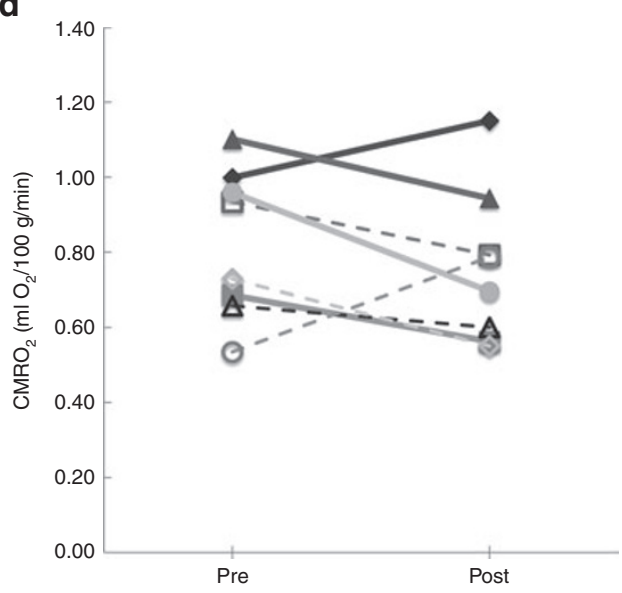

Figure 2. Individual values of pre- and post-single indomethacin treatment of patent ductus arteriosus for (a) cerebral blood flow (CBF), (b) cerebral blood volume (CBV), (c) oxygen extraction fraction (OEF), and (d) the cerebral metabolic rate of oxygen $\left(\mathrm{CMRO}_{2}\right)(n=8$, indomethacin dose $=0.2 \mathrm{mg} / \mathrm{kg})$. Data from each patient are represented by the same symbol and type of line in all graphs.

supply is sufficient to accommodate moderate variations in cerebral perfusion. Nevertheless, an increase in OEF does indicate that the cerebrovascular oxygen reserve is diminished by indomethacin, and any further reduction in either CBF or arterial oxygen tension during this period of vasoconstriction could potentially affect $\mathrm{CMRO}_{2}$.

The vasoconstricting effects of indomethacin are well known and are probably brought about by an action independent of its effect on prostaglandins because ibuprofen does not have the same effect on CBF (10). Other actions of indomethacin include inhibition of histamine release (26) and an enhancement of the lipoxygenase pathway (27). In addition, the effects of indomethacin on CBF appear to be dependent on the infusion rate. The 30-min infusion protocol used in the current study was based on a recent Cochrane review that recommended this duration to reduce perfusion effects without any loss of efficacy (28). The $18 \%$ reduction in CBF would appear to be in good agreement with the range of perfusion changes reported in previous studies using different infusion protocols. For the same dose, Patel et al. reported a greater CBF reduction $(40 \%)$ when indomethacin was infused over $15 \mathrm{~min}(10)$. Significant reductions in CBF velocities measured by Doppler ultrasound have also been reported for infusion durations of
Table 2. Clinical parameters and near-infrared spectroscopy measurements before and after indomethacin infusion

\begin{tabular}{lcc}
\hline Parameter & Pre-treatment & Post-treatment \\
\hline $\mathrm{BP}(\mathrm{mm} \mathrm{Hg})$ & $36.9 \pm 2.7$ & $38.7 \pm 2.8$ \\
$\mathrm{E}_{\mathrm{t}} \mathrm{CO}_{2}(\mathrm{~mm} \mathrm{Hg})$ & $56.1 \pm 2.4$ & $56.0 \pm 2.2$ \\
$\mathrm{pH}$ & $7.28 \pm 0.02$ & $7.25 \pm 0.01$ \\
$\mathrm{H}$ Heart rate $($ beats $/ \mathrm{min})$ & $152 \pm 4$ & $156 \pm 3$ \\
$\mathrm{~S}_{\mathrm{a}}(\%)$ & $93.6 \pm 1.9$ & $93.0 \pm 2.0$ \\
$\mathrm{CBF}(\mathrm{ml} / 100 \mathrm{~g} / \mathrm{min})$ & $12.9 \pm 1.3$ & $10.6 \pm 0.9^{*}$ \\
$\mathrm{CBV}(\mathrm{ml} / 100 \mathrm{~g})$ & $2.14 \pm 0.15$ & $1.73 \pm 0.10^{*}$ \\
$\mathrm{OEF}$ & $0.38 \pm 0.02$ & $0.42 \pm 0.02^{*}$ \\
$\mathrm{CMRO}_{2}(\mathrm{ml} \mathrm{O} / 100 \mathrm{~g} / \mathrm{min})$ & $0.83 \pm 0.07$ & $0.76 \pm 0.07$
\end{tabular}

Values are mean $\pm \operatorname{SE}(n=8)$.

$\mathrm{BP}$, blood pressure; $\mathrm{CBF}$, cerebral blood flow; $\mathrm{CBV}$, cerebral blood volume; $\mathrm{CMRO}_{2}$ cerebral metabolic rate of oxygen; $\mathrm{E}_{\mathrm{C}} \mathrm{CO}_{2}$, end-tidal carbon dioxide tension; $\mathrm{OEF}$, oxygen extraction fraction; $\mathrm{S}_{2} \mathrm{O}_{2}$, oxygen saturation.

*Significant change with treatment $(P<0.05)$.

the order of $30 \mathrm{~min}$ or less $(12,29)$. For durations greater than $2 \mathrm{~h}$, no significant change in CBF velocity was found $(29,30)$. Similarly, Lemmers et al. reported no change in cerebral blood oxygenation with a 60-min infusion protocol (5). 


\section{Articles $\mid$ Arora et al.}

In contrast to its effects on cerebral hemodynamics, the potential metabolic effects of indomethacin are less clear. Earlier NIRS studies reported significant reductions in the concentration of oxidized cytochrome oxidase after indomethacin infusion (16-18). The study by McCormick et al. used a 30-min infusion protocol similar to the one in the current study (17). However, it was concluded that the observed effects were more likely a result of a reduction in oxygen delivery (i.e., $\mathrm{CBF}$ ), rather than a direct effect on mitochondrial respiration because the concentration of oxidized cytochrome oxidase depends on the balance between oxygen delivery and utilization. Indirect evidence that indomethacin does not alter cerebral metabolism is found in the recent study showing no effects of the drug on electroencephalogram recording (31). Decreased $\mathrm{CMRO}_{2}$ has been reported in animal studies; however, these changes were found either at a high dose $(5 \mathrm{mg} / \mathrm{kg})$ or during hypotension $(32,33)$. Using the same infusion protocol and the same NIRS techniques, our group previously reported, in newborn piglets, that indomethacin significantly reduced CBF but had no effect on $\mathrm{CMRO}_{2}$ (34). These results substantiate the main finding of the current clinical study.

To the best of our knowledge, this study is the first in infants to report quantitative measurements of $\mathrm{CBF}$ and $\mathrm{CMRO}_{2}$ obtained using ICG as a contrast agent. The idea of using ICG for this purpose was initially proposed by Patel et al. to improve the precision of $\mathrm{CBF}$ measurements as compared with those obtained using the hemoglobin wash-in technique (23). However, their approach required the use of an arterial catheter to measure the arterial ICG concentration curve, $C_{a}(t)$. Our group has improved on this methodology by using dye densitometry to measure $C_{a}(t)$ noninvasively and incorporating a deconvolution routine in the data analysis to further improve the precision of the CBF measurements. Repeated measures demonstrated that CBF could be measured with a precision of better than $10 \%$ (22). The CBF and $\mathrm{CMRO}_{2}$ measurements obtained with this technique have been validated in multiple animal-model studies $(22,25)$.

In preterm infants, global CBF is expected to be in the order of $15 \mathrm{ml} / 100 \mathrm{~g} / \mathrm{min}$, which is in good agreement with the mean value reported in the current study $(12.9 \pm 1.3 \mathrm{ml} / 100 \mathrm{~g} / \mathrm{min})$ (35). Values in this range have been previously reported using a variety of perfusion techniques, including ${ }^{133}$ Xenon clearance and various NIRS methods $(10,20,35)$. An average $\mathrm{CMRO}_{2}$ of $0.83 \pm 0.06 \mathrm{ml} \mathrm{O}_{2} / 100 \mathrm{~g} / \mathrm{min}$ was also in good agreement with previous NIRS studies (19-21). Using the partial venous occlusion method, Yoxall and Weindling reported a median $\mathrm{CMRO}_{2}$ of $0.47 \mathrm{ml} \mathrm{O}_{2} / 100 \mathrm{~g} / \mathrm{min}$ for a group of 20 neonates with a median gestational age of $27 \mathrm{wk}$ (21). Elwell et al. reported a median $\mathrm{CMRO}_{2}$ of $1.03 \mathrm{ml} \mathrm{O} / 100 \mathrm{~g} / \mathrm{min}$ in a cohort of nine preterm infants with a median gestation age of $25 \mathrm{wk}$ (19). The approach used by Elwell et al. was similar to that of the current study given that estimates of cerebral venous saturation were obtained assuming a venous fraction of 0.75 .
One limitation of this study was the occurrence of motion artifacts during the 60-s recording period, which was primarily a challenge for measuring the arterial ICG concentration curve by dye densitometry. To minimize motion, the acquisition of the ICG data was often delayed 5-10 min after placing the NIRS and dye densitometer probes on the head and hand, respectively. However, it is very difficult to control for all motions and, in this small cohort of 10 patients, it was necessary to omit two data sets. This failure rate is similar to that of the study by Leung et al., in which 7 of 25 trials (28\%) were excluded using dye densitometry to measure CBV (36). Another limitation of the current study was that the number of $\mathrm{CBF}$ measurements was restricted to two because of safety concerns with injecting an exogenous contrast agent. This prevented monitoring CBF during indomethacin infusion to determine if CBF potentially falls to lower values, or monitoring for longer period after the injection to determine when $\mathrm{CBF}$ returned to preinfusion levels. One solution would be to combine the ICG bolus-tracking method with diffuse correlation spectroscopy to provide continuous monitoring of CBF without the need for repeat ICG injections (37).

In this study, we used a previously validated NIRS method to investigate the effects of indomethacin on $\mathrm{CBF}$ and $\mathrm{CMRO}_{2}$ in preterm infants with clinically significant PDA. The results confirmed the expected decrease in $\mathrm{CBF}$ following indomethacin infusion; however, $\mathrm{CMRO}_{2}$ remained at preinfusion levels due to a significant increase in the OEF. These findings of decreased $\mathrm{CBF}$ with preserved $\mathrm{CMRO}_{2}$ may help explain why indomethacin prophylaxis decreases the incidence of severe intraventricular hemorrhage, being that $\mathrm{CMRO}_{2}$ probably remains stable during large arterial $\mathrm{BP}$ fluctuations (38). The baseline $\mathrm{CBF}$ and $\mathrm{CMRO}_{2}$ values were also in good agreement with previous studies. These results suggest that this methodology could be used for bedside assessments with other clinical conditions that have the potential to affect cerebral hemodynamics and energy metabolism.

\section{METHODS}

\section{Patient Population}

Preterm infants (gestational age $<30 \mathrm{wk}$ ) with hemodynamically significant PDA were enrolled in the study after obtaining informed and written parental consent. The diagnosis of PDA was based on clinical indexes (systolic murmur, wide pulse pressure, increased respiratory support, and metabolic acidosis) and confirmed by echocardiography (left atrium/aorta ratio $>1.4$, internal ductal diameter $>2 \mathrm{~mm}$, and/or left pulmonary artery end diastolic flow velocity $>0.2 \mathrm{~m} / \mathrm{s}$ ). Infants were excluded if diagnosed with severe intraventricular hemorrhage (grade III or IV, Papile classification), major congenital malformations, or persistent hypotension requiring inotropic support. The study was approved by the Health Sciences Research Ethics Board of Western University, London, Ontario, Canada.

\section{NIRS}

All NIRS data were collected with a continuous-wave, broadband (600$980 \mathrm{~nm}$ ) system using two fiber-optic bundles, one for light emission and the other for detection (22). The ends of the fiber bundles were held $3.5 \mathrm{~cm}$ apart using a custom-built holder that was strapped to the infant's head to position the probes over the frontoparietal region. The concentrations of ICG and [HHb] were determined by secondderivative spectroscopy (39). With this approach, light attenuation is converted into chromophore concentration assuming water content in brain of $85 \%$. 
The NIRS technique for measuring CBF required an intravenous bolus injection of ICG (22). The time-dependent concentration of ICG in brain, $Q(t)$, is related to CBF by the following equation:

$$
Q(t)=C B F \int_{0}^{t} C_{a}(u) \cdot R(t-u) d u
$$

where $Q(t)$ was determined from the NIRS absorption measurements acquired at a temporal resolution of $200 \mathrm{~ms}$. The time-dependent concentration of ICG in arterial blood, $C_{a}(t)$, was measured noninvasively by a dye densitometer (DDG-2001 A/K, Nihon Kohden, Tokyo, Japan) attached to a foot. The remaining function, $R(t)$, is the impulse residue function; it represents the amount of ICG in brain tissue following an idealized bolus injection of unit concentration (40). The product CBF. $R(t)$ was extracted from the measured $Q(t)$ and $C_{a}(t)$ data by deconvolution (22). The initial height corresponds to CBF because by definition, $R(t)$ has an initial value of 1 , and CBV was determined from the area under CBF. $R(t)$.

The method used to calculate $\mathrm{CMRO}_{2}$ was based on the Fick principle:

$$
\mathrm{CMRO}_{2}=\mathrm{CBF} \cdot \mathrm{AVDO}_{2}
$$

where $\mathrm{AVDO}_{2}$ is the cerebral arteriovenous oxygen difference. Because the second-derivative method does not provide a reliable estimate of oxyhemoglobin (39), the venous concentration of oxygen, $\left[\mathrm{O}_{2}\right]_{v}$, was determined from the NIRS $[\mathrm{HHb}]$ measurement acquired before injecting ICG (25):

$$
\left[\mathrm{O}_{2}\right]_{v}=1.39 \cdot\left([t \mathrm{Hb}]-\frac{1}{f_{v}}\left(\frac{[\mathrm{HHb}]}{\mathrm{CBV} \cdot \rho}-\left(1-f_{v}\right)[\mathrm{HHb}]_{\alpha}\right)\right)
$$

where the factor 1.39 describes the amount of $\mathrm{O}_{2}$ (in $\mathrm{ml}$ ) bound per gram of hemoglobin; $[t \mathrm{Hb}]$ is the total hemoglobin concentration; $\rho$ is the density of brain tissue $(1.05 \mathrm{~g} / \mathrm{ml})$; $[\mathrm{HHb}]_{a}$ is the arterial concentration of deoxyhemoglobin, which was determined from the arterial $\mathrm{S}_{\mathrm{a}} \mathrm{O}_{2}$; and $f_{v}$ is the assumed venous blood fraction (0.75). In this equation, the term $\mathrm{CBV} \cdot \rho$ converts the NIRS tissue [HHb] measurement to an equivalent blood measurement.

The fraction of oxygen extracted into brain, OEF, was calculated by

$$
\mathrm{OEF}=\frac{\left[\mathrm{O}_{2}\right]_{a}-\left[\mathrm{O}_{2}\right]_{v}}{\left[\mathrm{O}_{2}\right]_{a}}
$$

\section{Study Design}

Pharmacological treatment of PDA followed the standard indomethacin dosage schedule consisting of three doses of $0.2 \mathrm{mg} / \mathrm{kg}$, separated by $24 \mathrm{~h}$, infused intravenously over $30 \mathrm{~min}$. Two NIRS data sets were acquired on the first day of treatment, one $\sim 5 \mathrm{~min}$ before the start of drug infusion and the other immediately at the end of 30-min infusion. The acquisition period for each ICG run was $\sim 80 \mathrm{~s}$, with the dye injected $(0.1 \mathrm{mg} / \mathrm{kg}$ at a concentration of $0.5 \mathrm{mg} / \mathrm{ml}$ sterile water, BCD Pharma, Mississauga, Ontario, Canada) around the $10 \mathrm{~s}$ mark using a preexisting central-line catheter. The tissue and arterial ICG concentration curves were acquired simultaneously by NIRS and the dye densitometer, respectively. The fiber-optic probes remained in the same position on the head throughout the treatment to eliminate potential variations associated with probe re-positioning. Clinical data, including $\mathrm{S}_{\mathrm{a}} \mathrm{O}_{2}$, heart rate, $\mathrm{BP}$, transcutaneous carbon dioxide, capillary blood gases and $[t \mathrm{Hb}]$, the mode of ventilation, and urine output, were also recorded.

\section{Statistical Analysis}

SPSS 15.0 (SPSS, Chicago, IL) was used for all statistical analysis. A paired $t$ test was used to determine significant differences before and after indomethacin infusion. The analysis was conducted for $\mathrm{CBF}, \mathrm{OEF}$, and $\mathrm{CMRO}_{2}$, as well as for clinical parameters measured pre- and post-treatment $\left(\mathrm{S}_{\mathrm{a}} \mathrm{O}_{2}\right.$, heart rate, $\mathrm{BP}, \mathrm{pH}$, and transcutaneous carbon dioxide). Statistical significance for all tests was based on a $P$ value $<0.05$. All data are presented as mean $\pm \mathrm{SE}$, unless otherwise stated.

\section{ACKNOWLEDGMENTS}

We acknowledge and thank Richa Mehta, the project secretary; Jamie Seabrook for his help with the statistics; and Kenneth Tichauer for his help with data collection and instructional support.

\section{STATEMENT OF FINANCIAL SUPPORT}

This work was supported by grants from the Canadian Institutes of Health Research and the Internal Research Fund of the Lawson Health Research.

Disclosure: The authors declared no conflict of interest.

\section{REFERENCES}

1. The Vermont-Oxford Trials Network: very low birth weight outcomes for 1990. Investigators of the Vermont-Oxford Trials Network Database Project. Pediatrics 1993;91:540-5.

2. Ellison RC, Peckham GJ, Lang P, et al. Evaluation of the preterm infant for patent ductus arteriosus. Pediatrics 1983;71:364-72.

3. Antonucci R, Bassareo P, Zaffanello M, Pusceddu M, Fanos V. Patent ductus arteriosus in the preterm infant: new insights into pathogenesis and clinical management. J Matern Fetal Neonatal Med 2010;23:Suppl 3:34-7.

4. Laughon MM, Simmons MA, Bose CL. Patency of the ductus arteriosus in the premature infant: is it pathologic? Should it be treated? Curr Opin Pediatr 2004;16:146-51

5. Lemmers PM, Toet MC, van Bel F. Impact of patent ductus arteriosus and subsequent therapy with indomethacin on cerebral oxygenation in preterm infants. Pediatrics 2008;121:142-7.

6. Cooke L, Steer P, Woodgate P. Indomethacin for asymptomatic patent ductus arteriosus in preterm infants. Cochrane Database Syst Rev 2003;2:CD003745.

7. Ohlsson A, Walia R, Shah SS. Ibuprofen for the treatment of patent ductus arteriosus in preterm and/or low birth weight infants. Cochrane Database Syst Rev 2010;1:CD003481.

8. Thomas RL, Parker GC, Van Overmeire B, Aranda JV. A meta-analysis of ibuprofen versus indomethacin for closure of patent ductus arteriosus. Eur J Pediatr 2005;164:135-40.

9. Pryds O, Greisen G, Johansen KH. Indomethacin and cerebral blood flow in premature infants treated for patent ductus arteriosus. Eur J Pediatr 1988;147:315-6.

10. Patel J, Roberts I, Azzopardi D, Hamilton P, Edwards AD. Randomized double-blind controlled trial comparing the effects of ibuprofen with indomethacin on cerebral hemodynamics in preterm infants with patent ductus arteriosus. Pediatr Res 2000;47:36-42.

11. Edwards AD, Wyatt JS, Richardson C, et al. Effects of indomethacin on cerebral haemodynamics in very preterm infants. Lancet 1990;335: 1491-5.

12. Evans DH, Levene MI, Archer LN. The effect of indomethacin on cerebral blood-flow velocity in premature infants. Dev Med Child Neurol 1987;29:776-82.

13. Ohlsson A, Bottu J, Govan J, Ryan ML, Fong K, Myhr T. Effect of indomethacin on cerebral blood flow velocities in very low birth weight neonates with a patent ductus arteriosus. Dev Pharmacol Ther 1993;20:100-6.

14. Keating P, Verhagen E, van Hoften J, ter Horst H, Bos AF. Effect of indomethacin infused over 30 minutes on cerebral fractional tissue oxygen extraction in preterm newborns with a patent ductus arteriosus. Neonatology 2010;98:232-7.

15. Garner RS, Miller C, Burchfield DJ. Prophylactic indomethacin infusion increases fractional cerebral oxygen extraction in ELBW neonates. J Perinatol 2012;32:695-8.

16. Mosca F, Bray M, Lattanzio M, Fumagalli M, Tosetto C. Comparative evaluation of the effects of indomethacin and ibuprofen on cerebral perfusion and oxygenation in preterm infants with patent ductus arteriosus. J Pediatr 1997;131:549-54. 
17. McCormick DC, Edwards AD, Brown GC, et al. Effect of indomethacin on cerebral oxidized cytochrome oxidase in preterm infants. Pediatr Res 1993;33:603-8.

18. Liem KD, Hopman JC, Kollée LA, Oeseburg B. Effects of repeated indomethacin administration on cerebral oxygenation and haemodynamics in preterm infants: combined near infrared spectrophotometry and Doppler ultrasound study. Eur J Pediatr 1994;153:504-9.

19. Elwell CE, Henty JR, Leung TS, et al. Measurement of $\mathrm{CMRO}_{2}$ in neonates undergoing intensive care using near infrared spectroscopy. Adv Exp Med Biol 2005;566:263-8.

20. Kissack CM, Garr R, Wardle SP, Weindling AM. Cerebral fractional oxygen extraction is inversely correlated with oxygen delivery in the sick, newborn, preterm infant. J Cereb Blood Flow Metab 2005;25:545-53.

21. Yoxall CW, Weindling AM. Measurement of cerebral oxygen consumption in the human neonate using near infrared spectroscopy: cerebral oxygen consumption increases with advancing gestational age. Pediatr Res 1998;44:283-90.

22. Brown DW, Picot PA, Naeini JG, Springett R, Delpy DT, Lee TY. Quantitative near infrared spectroscopy measurement of cerebral hemodynamics in newborn piglets. Pediatr Res 2002;51:564-70.

23. Patel J, Marks K, Roberts I, Azzopardi D, Edwards AD. Measurement of cerebral blood flow in newborn infants using near infrared spectroscopy with indocyanine green. Pediatr Res 1998;43:34-9.

24. Garski TR, Staller BJ, Hepner G, Banka VS, Finney RA Jr. Adverse reactions after administration of indocyanine green. JAMA 1978;240:635.

25. Tichauer KM, Hadway JA, Lee TY, St Lawrence K. Measurement of cerebral oxidative metabolism with near-infrared spectroscopy: a validation study. J Cereb Blood Flow Metab 2006;26:722-30.

26. König W, Brom J, Schönfeld W, Knöller J, Stüning M. Effect of tenoxicam and indomethacin on the release of histamine, prostaglandin E2 and leukotrienes from various cells. Arzneimittelforschung 1987;37:296-9.

27. Docherty JC, Wilson TW. Indomethacin increases the formation of lipoxygenase products in calcium ionophore stimulated human neutrophils. Biochem Biophys Res Commun 1987;148:534-8.

28. Görk AS, Ehrenkranz RA, Bracken MB. Continuous infusion versus intermittent bolus doses of indomethacin for patent ductus arteriosus closure in symptomatic preterm infants. Cochrane Database Syst Rev 2008;1:CD006071.
29. Hammerman C, Glaser J, Schimmel MS, Ferber B, Kaplan M, Eidelman AI. Continuous versus multiple rapid infusions of indomethacin: effects on cerebral blood flow velocity. Pediatrics 1995;95:244-8.

30. Kondo M, Kunikata T, Okazaki K, Yasuda S, Isobe K, Itoh S. Relation between infusion rate of indomethacin and cerebral blood flow velocity. Pediatr Int 2010;52:616-21.

31. Flisberg A, Kjellmer I, Löfhede J, et al. Does indomethacin for closure of patent ductus arteriosus affect cerebral function? Acta Paediatr 2010;99:1493-7.

32. Pourcyrous M, Leffler CW, Bada HS, Korones SB, Busija DW. Cerebral blood flow responses to indomethacin in awake newborn pigs. Pediatr Res 1994;35:565-70.

33. Leffler CW, Busija DW, Beasley DG. Effect of therapeutic dose of indomethacin on the cerebral circulation of newborn pigs. Pediatr Res 1987;21:188-92.

34. Brown DW, Lee D, Kumaran VS, Lee TY. Age-dependent cerebral hemodynamic effects of indomethacin in the newborn piglet. J Appl Physiol 2004;97:1880-7.

35. Greisen G. Cerebral blood flow in preterm infants during the first week of life. Acta Paediatr Scand 1986;75:43-51.

36. Leung TS, Aladangady N, Elwell CE, Delpy DT, Costeloe K. A new method for the measurement of cerebral blood volume and total circulating blood volume using near infrared spatially resolved spectroscopy and indocyanine green: application and validation in neonates. Pediatr Res 2004;55:134-41.

37. Diop M, Verdecchia K, Lee TY, St Lawrence K. Calibration of diffuse correlation spectroscopy with a time-resolved near-infrared technique to yield absolute cerebral blood flow measurements. Biomed Opt Express 2011;2:2068-81.

38. Schmidt B, Davis P, Moddemann D, et al.; Trial of Indomethacin Prophylaxis in Preterms Investigators. Long-term effects of indomethacin prophylaxis in extremely-low-birth-weight infants. N Engl J Med 2001;344:196672.

39. Matcher SJ, Cope M, Delpy DT. Use of the water absorption spectrum to quantify tissue chromophore concentration changes in near-infrared spectroscopy. Phys Med Biol 1994;39:177-96.

40. Zierler KL. Equations for measuring blood flow by external monitoring of radioisotopes. Circ Res 1965;16:309-21. 